\title{
A SOFTWARE TO PROMOTE INTERACTIVE TEACHING OF WATER PROPERTIES IN BIOCHEMISTRY CLASSES
}

\author{
Lapouble, O.M.M.; Veloso, C.E.R.; Neves, G.R.; Castro, M.S.; Fontes, W.
}

Laboratório de Bioquímica e Química de Proteínas, Departamento de Biologia Celular, Universidade de Brasília, Brasília/DF

The improvement and development of new tools in design and informatics helped the creation of biochemistry teaching material. Many molecules, metabolic pathways, reactions, and interactions are best explained and understood when shown in three dimensions and allowing interactivity. Water is, usually, the first topic to be presented during basic biochemistry courses. Importance, properties, ionization, $\mathrm{pH}$, buffering and titration curves, are frequently presented subjects, but static graphics dont show to students the interactions between water molecules, interactions with the solutes and buffer titration in a clear way. In this work, Flash software from Macromedia, was used to produce the llustrations, animations, and ActionScript programming was used to simulate the titration of some buffers and correlate the molecular concept to the graphic charts.

With this work, we are trying to improve the quality of biochemistry teaching material, and to show, in a clear way, subjects that are difficult to explain by static graphics limitation. This material could be used in regular classes, to be projected or showed in computers and could be used by students in self-guided study because it allows optional visualization of texts. An assisted navigation tool could suggest to students, a sequence of topics but still allowing the freedom of choice of any available topic.

Supported by: FUB/UnB 